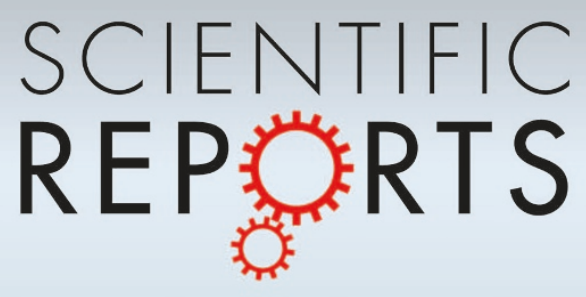

OPEN

SUBJECT AREAS:

MOLECULAR SELF-

ASSEMBLY

SELF-ASSEMBLY

PHASE TRANSITIONS AND CRITICAL PHENOMENA

COLLOIDS

Received

26 February 2013

Accepted

28 March 2013

Published

16 April 2013

Correspondence and requests for materials should be addressed to J.C.H. lihao@sdu.edu.

$\mathrm{cn})$

\title{
Molecular Aggregates in Stable Aqueous Three-Phase Surfactant Systems and Their use in Producing CdS Nanowires
}

\author{
Renhao Dong, Liang Zhou, Dong Wang \& Jingcheng Hao
}

Key Laboratory of Colloid and Interface Chemistry \& Key Laboratory of Special Aggregated Materials, Shandong University, Ministry of Education, Jinan 250100, China.

Aqueous three-phase surfactant systems (A3PS) are important, multicomponent, stable three-phase equilibria with coexisting forms in a common colloid solution, but have been largely ignored regarding further characterization and application. Mixing simple, commercially available, single-tailed anionic/ nonionic or anionic/cationic surfactants in water can spontaneously produce stable A3PS with coexisting multiscale self-assembled structures including discs, lamellas, micelles and vesicles. As with conventional aqueous two-phase systems (A2PS), A3PS can be applied in partition and extraction processes. Here, the A3PS was also used as a mild media for one-step synthesis of multiscale CdS nanowires. Particularly, the A3PS does not change and simultaneously separates the CdS nanowires with the comparable size in one phase, which provides a facile strategy for collection of monodisperse nanomaterials. We expect that this present work can expand recognition of A3PS for use in theoretical and applied studies.

M olecular self-assembly, via non-covalent interactions, has been recognized as a fascinating, practical, bottom-up approach to achieve stable, structurally well-defined, and functional objects at the nano- and microscale in biological systems and materials synthesis ${ }^{1,2}$. While a large number of self-assembled forms such as micelles, discs, vesicles, tubes, and fibers have been reported in aqueous solutions of natural or synthetic amphiphiles ${ }^{3-8}$, the future development of self-assembly should see a move towards the construction of variably-scaled multicomponent complex systems with diverse function.

Aqueous multiphase separation is an interesting assembly process in colloid science that results in a higher degree of complexity in the system but can be readily achieved by a variety of easily accessible conditions and components. In particular, aqueous two-phase systems (A2PS), introduced by the pioneering work of Albertsson', have been acknowledged to develop biotechnical processes for the recovery and purification of many biological materials including proteins, nucleic acids, and cells ${ }^{10-12}$. A conventional A2PS consists of two incompatible hydrophilic polymers, or a hydrophilic polymer and a salt, with water as continuous medium. Each of the phases obtained is enriched in one of the components. In addition, liquid-liquid phase separation upon heating above component cloud point is a common phenomenon in dilute nonionic surfactant solutions, where one phase becomes rich in surfactant and the other poor ${ }^{13}$. In recent years, many new A2PSs, including anionic/nonionic ${ }^{14}$ and anionic/cationic (catanionic) surfactants ${ }^{15}$, have been designed for applications in separations and purification processes.

In contrast, there has been no special exploration of aqueous three-phase surfactant systems (A3PS) for separations or other applications. In fact, the previous aqueous three-phase systems were also formed by mixing nonionic surfactants and two types of polymers in water. At present, the A3PSs have been frequently reported in phase diagrams of pure surfactant solutions $s^{3,16-18}$. Hoffmann et al..$^{3}$ determined some three-phase regions such as micelle/micelle/lamella $\left(\mathrm{L}_{1} / \mathrm{L}_{1} / \mathrm{L} \alpha\right)$ and lamella/sponge/micelle $\left(\mathrm{L} \alpha / \mathrm{L}_{3} / \mathrm{L}_{1}\right)$ in aqueous solution of tetradecyldimethylamine oxide and medium alcohol. Other surfactant works also reported the lamella/sponge/micelle $\left(\mathrm{L} \alpha / \mathrm{L}_{3} / \mathrm{L}_{1}\right)$ three-phase in sodium bis(2-ethyl hexyl)sulfosuccinate $/ \mathrm{NaCl} / \mathrm{H}_{2} \mathrm{O}$ system ${ }^{16}$ and reversed micelle/ lamella/hexagonal structure $\left(\mathrm{L}_{2} / \mathrm{L} \alpha / \mathrm{H}_{1}\right)$ three-phase in tetraethylene glycol monododecyl ether/sucrose ester/ decane/ $\mathrm{H}_{2} \mathrm{O}$ system ${ }^{18}$. However, the aggregate details of these three-phases have not been confirmed by direct observation until now. For example, it is attractive to confirm the differences between the two separated micellar phases in the above $\mathrm{L}_{1} / \mathrm{L}_{1} / \mathrm{L} \alpha$ solution. Therefore, the confirmation of complex self-assembled forms, the establishment of simple three-phase models, and the characterization of important physicochemical properties for A3PS are significant, timely issues. Furthermore, as a coexisting multiphasic equilibrium system with 
rich complexity, A3PS can exhibit higher partition efficiency for biomaterials or other species. As might be expected, the present lack of a general method for the production of A3PS has hindered its development and application.

To help generalize the characterization and modification of A3PS properties, we report here aqueous mixtures of anionic/nonionic and anionic/cationic surfactants that produce aqueous three-phase systems: (i) sodium dodecylethoxysulfonate $\left(\mathrm{CH}_{3}\left(\mathrm{CH}_{2}\right)_{11}\left(\mathrm{CH}_{2} \mathrm{CH}_{2} \mathrm{O}\right)_{2.5}\right.$ $\mathrm{SO}_{3} \mathrm{Na}$, Texapon $\left.\mathrm{N}_{70}\right)$ /tetradecyldimethylamine oxide $\left(\mathrm{C}_{14} \mathrm{DMAO}\right)$ / formic acid ( $\mathrm{HCOOH})$, (ii) lauric acid $\left(\mathrm{CH}_{3}\left(\mathrm{CH}_{2}\right)_{10} \mathrm{COOH}, \mathrm{LA}\right) /$ tetraethylene glycol monododecyl ether $\left[\mathrm{CH}_{3}\left(\mathrm{CH}_{2}\right)_{11}\left(\mathrm{CH}_{2} \mathrm{CH}_{2} \mathrm{O}\right)_{4} \mathrm{OH}\right.$, $\left.\mathrm{C}_{12} \mathrm{EO}_{4}\right]$, and (iii) sodium laurate (SL)/tetradecyltrimethylammonium bromide (TTABr). Using system (i) as a model system, we also present the application of A3PS for the solubilization and partition of dyes, and one-step synthesis and separation of multiscale CdS nanowires in one common three-phase solution.

\section{Results}

After the three surfactant systems were kept at constant temperature for one month, two clearly visible liquid-liquid phase boundaries were observed separating each system into three aqueous phases. Sample photographs, taken after 12 months, revealed that the apparent phase behavior remained without obvious change, implying that these A3PSs are stable. A common feature of the three systems is that one of their phases shows significant birefringence under crossed polarizers while the other two phases are transparent and lack birefringence (Fig. S1). Each phase of the three samples takes up a different phase volume fraction. These preliminary observations led us to question how the surfactant mixtures are distributed in the three aqueous phases, and what complex self-assembled forms exist in these three phase systems.

A3PS in anionic/nonionic system of Texapon $\mathrm{N}_{70} / \mathrm{C}_{14} \mathrm{DMAO} /$ $\mathrm{HCOOH} / \mathrm{H}_{2} \mathrm{O}$. Cryogenic transmission electron microscopy (cryoTEM), dynamic light scattering (DLS), elemental analysis, density and volume fraction measurements, and $\mathrm{pH}$ measurements were employed to determine the inherent properties of the A3PS. As expected, the system (i) exhibits typical behavior of an anionic/ cationic system. Because the weakly basic, nonionic $\mathrm{C}_{14} \mathrm{DMAO}$ can be easily protonated by $\mathrm{HCOOH}$, ion pairs form through the electrostatic interaction between $\mathrm{C}_{14} \mathrm{DMAOH}^{+}\left(\mathrm{C}_{14} \mathrm{DMAO}+\right.$ $\mathrm{HCOOH} \rightarrow \mathrm{C}_{14} \mathrm{DMAOH}^{+}+\mathrm{HCOO}^{-}$) and the sulfate group of Texapon $\mathrm{N}_{70}$. This ion-pairing, in combination with hydrophobic interactions, results in the self-assembly process. The phase diagram for $100 \mathrm{mM} \mathrm{C}_{14} \mathrm{DMAO}$ as a function of the concentration of Texapon $\mathrm{N}_{70}$ with equimolar concentrations of $\mathrm{HCOOH}$ at $25^{\circ} \mathrm{C}$ is shown in Fig. S2. Previously ${ }^{17}$, it was observed that increasing Texapon $\mathrm{N}_{70}$ and formic acid concentrations resulted in a series of phase transitions. In this system, the three-phase region exists in a very narrow concentration region of 26 to $26.8 \mathrm{mM}$ Texapon $\mathrm{N}_{70}$.

Fig. 1a shows the optical photographs of three-phase samples with and without crossed polarizers. In the top phase of a sample of $26.5 \mathrm{mM}$ Texapon $\mathrm{N}_{70} / 100 \mathrm{mM} \mathrm{C}_{14} \mathrm{DMAO} / 26.5 \mathrm{mM} \mathrm{HCOOH}$, at Texapon $\mathrm{N}_{70} / \mathrm{C}_{14} \mathrm{DMAO}$ molar ratio of 0.25 determined by elemental analysis (Table 1), one observes monodisperse nanodiscs with a mean diameter of $12 \pm 3 \mathrm{~nm}$ coexisting with a few flexible bilayer fragments of over $100 \mathrm{~nm}$ in length (Fig. 1b). Coexistence of different microstructures of differing size can be easily identified by DLS, as shown in Fig. 2, for the top, middle, and bottom phases of this system at scattering angle of $90^{\circ}$. The hydrodynamic radius $\left(R_{h}\right)$ obtained by CONTIN analysis ${ }^{19}$ confirmed the presence of two different aggregates in the top phase with mean sizes of $10 \mathrm{~nm}$ and $150 \mathrm{~nm}$ that may be assigned to the nanodiscs and bilayer fragments, respectively. The isolated nanodiscs lie with an edge-on orientation and appear as dark lines with tapered ends in the cryo-TEM images $^{20,21}$. The calculated $\mathrm{pH}$ value of a $26.5 \mathrm{mM}$ formic acid aqueous solution is about 2.68 , however, the $\mathrm{pH}$ was measured to be $5.75 \pm 0.05$ in the three-phase solution, indicating that most of formic acid reacted with the weakly basic $\mathrm{C}_{14} \mathrm{DMAO}$ to form $\mathrm{C}_{14} \mathrm{DMAOH}^{+}$. The presence of a small amount of $\mathrm{H}_{3} \mathrm{O}^{+}$in solution indicates an incomplete protonation of $\mathrm{C}_{14} \mathrm{DMAO}$; therefore, the nanodiscs possess a small excess of basic surfactant, giving the nanodisc edges anionic character ${ }^{5}$.

In the slightly turbid birefringent mid-phase at Texapon $\mathrm{N}_{70}$ / $\mathrm{C}_{14} \mathrm{DMAO}$ ratios of 0.31 , the cryo-TEM image shows very long bilayer fragments of several hundred nm (Fig. 1c). These lamellas are irregular, even distorted, and appear flexible. DLS results (Fig. 2) also indicate the polydispersion of these bilyer fragments that the average sizes are concentrated in about $10 \mathrm{~nm}, 30 \mathrm{~nm}$ and $300 \mathrm{~nm}$, respectively. In the transparent bottom phase at Texapon $\mathrm{N}_{70}$ / $\mathrm{C}_{14}$ DMAO ratio of 0.32 , a rearrangement of the surfactant results in a phase transition from large lamellas back to monodisperse, negatively charged nanodiscs with a mean diameter of $24 \pm 4 \mathrm{~nm}$ (Fig. 1d). DLS also confirms their formation with a resulting mean $R_{h}$ of $35 \mathrm{~nm}$ (Fig. 2). In this phase some nanodiscs lie in an edge-on orientation and appear as dark bars (filled arrows in Fig. 1d), while discs in a face-on orientation appear as circles or as variably elongated ellipses (open arrows). Some of the observed differences in the morphologies of the discs results from the thickness of the vitrified aqueous film as prepared for cryo-TEM analysis ${ }^{21}$.

From the top phase to the middle phase of the sample, the structure transforms from nanodiscs $\left(\mathrm{L}_{1}{ }^{\prime}\right)$ to large lamellas $(\mathrm{L} \alpha)$, accompanied with an increase in the Texapon $\mathrm{N}_{70} / \mathrm{C}_{14} \mathrm{DMAO}$ ratio, solution density, and phase volume fraction (Table 1). On the other hand, the bottom phase, also a nanodisc region $\left(\mathrm{L}_{1}{ }^{\prime}\right)$, possessed the highest Texapon $\mathrm{N}_{70} / \mathrm{C}_{14} \mathrm{DMAO}$ ratio and solution density, but the smallest volume. These macroscopic and microscopic changes reveal the structures and properties of the aqueous three-phase $\left(\mathrm{L}_{1}{ }^{\prime} / \mathrm{L} \alpha / \mathrm{L}_{1}{ }^{\prime}\right)$ that is related to the coexistence of complex aggregates and different surfactant compositions, as well as the resulting differences in solution density among the three phases. However, it is not known whether the aqueous three-phase formation is unique phenomenon in specific surfactant systems, or a more general phenomenon. In this system, excess salt is present with the two single-tailed anionic/nonionic surfactants. For comparison, the $\mathrm{LA} / \mathrm{C}_{12} \mathrm{EO}_{4} / \mathrm{H}_{2} \mathrm{O}$ anionic/

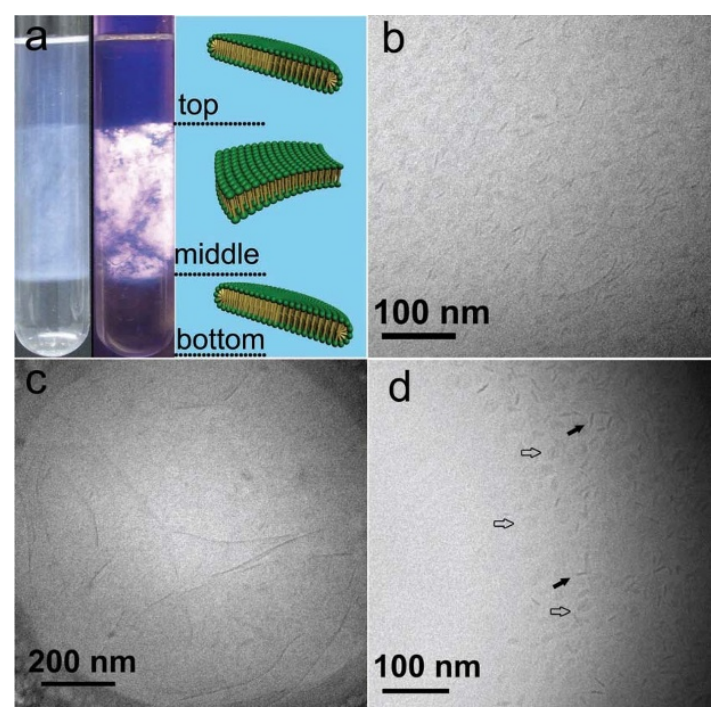

Figure $1 \mid$ Molecular aggregates of A3PS in Texapon $\mathrm{N}_{70} / \mathrm{C}_{14} \mathrm{DMAO} /$ $\mathrm{HCOOH} / \mathrm{H}_{2} \mathrm{O}$ at $25^{\circ} \mathrm{C}$. (a) Optical photographs of three-phase samples with and without crossed polarizers. Cryo-TEM images of nanodiscs, distorted bilayers, and nanodiscs in the top (b), middle (c), and bottom (d) phases, respectively. Open and filled arrows indicate discs in face-on and edge-on orientations, respectively (b). 
Table 1 | Physicochemical parameters for the aqueous three-phase systems

\begin{tabular}{|c|c|c|c|}
\hline Samples & Top phase & Middle phase & Bottom phase \\
\hline 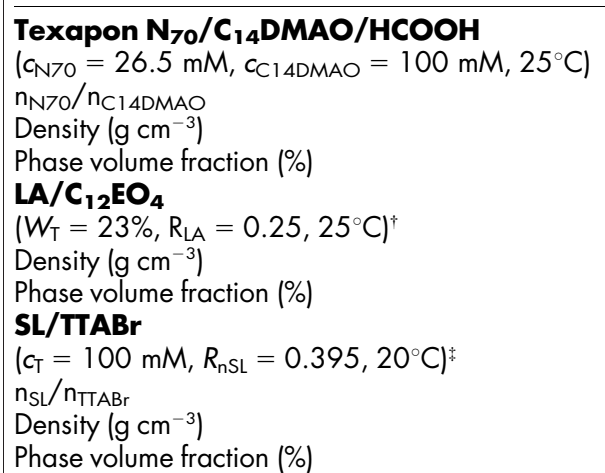 & $\begin{array}{l}\text { discs } \\
\left(L_{1}{ }^{\prime}\right) \\
0.25 \\
0.893 \\
31 \\
\text { vesicles } \\
\left(L \alpha^{\prime}\right) \\
0.828 \\
36 \\
\text { lamellas } \\
(L \alpha) \\
0.62 \\
0.718 \\
5\end{array}$ & $\begin{array}{c}\text { lamellas } \\
(L \alpha) \\
0.31 \\
1.050 \\
40 \\
\text { sponge structures } \\
\left(L_{3}\right) \\
0.985 \\
49 \\
\text { threadlike micelles } \\
\left(L_{1}\right) \\
0.57 \\
0.814 \\
47\end{array}$ & $\begin{array}{l}\text { discs } \\
\left(\mathrm{L}_{1}^{\prime}\right) \\
0.32 \\
1.165 \\
29 \\
\text { discs } \\
\left(\mathrm{L}_{1}{ }^{\prime}\right) \\
1.021 \\
15 \\
\text { vesicles } \\
\left(\mathrm{L} \alpha^{\prime}\right) \\
0.82 \\
1.216 \\
48\end{array}$ \\
\hline
\end{tabular}

nonionic system was investigated to identify whether excess salt is a necessary for the formation of A3PS.

A3PS in salt-free anionic/nonionic system of $\mathrm{LA} / \mathrm{C}_{12} \mathrm{EO}_{4} / \mathrm{H}_{2} \mathrm{O}$. LA has a very low solubility in water, but dissolves in $\mathrm{C}_{12} \mathrm{EO}_{4}$ aqueous solution with a release of $\mathrm{H}^{+}$. Thus, the $\mathrm{LA} / \mathrm{C}_{12} \mathrm{EO}_{4}$ mixture behaves as anionic/cationic mixture system because the oxygen atoms in $\mathrm{C}_{12} \mathrm{EO}_{4}$ are partially protonated, resulting in a partial positive charge on the nonionic surfactant. The competition among the extra electrostatic interactions, the hydrophobic interaction and membrane undulation induces a rather rich phase behavior in the mixture. The phase diagram of the $\mathrm{LA} / \mathrm{C}_{12} \mathrm{EO}_{4} / \mathrm{H}_{2} \mathrm{O}$ system at $25^{\circ} \mathrm{C}$ is shown in Fig. S3. The three-phase region is present in the range of $W_{\mathrm{T}}=10 \%$ to $30 \%$ and $R_{\mathrm{LA}}=0.225$ to 0.275 .

In a three-phase sample of $\mathrm{LA} / \mathrm{C}_{12} \mathrm{EO}_{4} / \mathrm{H}_{2} \mathrm{O}$ system with $W_{\mathrm{T}}=$ $23 \%$ and $R_{\mathrm{LA}}=0.25$ (Fig. 3a), the clear upper phase has an obvious birefringence indicating the presence of anisotropic aggregate structures. This is confirmed by cryo-TEM images that show small unilamellar vesicles (Fig. 3b) with diameters ranging from 50 to $120 \mathrm{~nm}$. The self-fusion of aggregates, where smaller vesicles were swallowed by larger vesicles or two vesicles merging together, was observed. In the three-phase systems, the $\mathrm{pH}$ was measured to be $3.30 \pm 0.05$. The excess $\mathrm{H}_{3} \mathrm{O}^{+}$in solution indicates net negative charges on the membrane surface due to unpaired anionic surfactants. In the middle phase, the three-dimensional network structure of spherical and

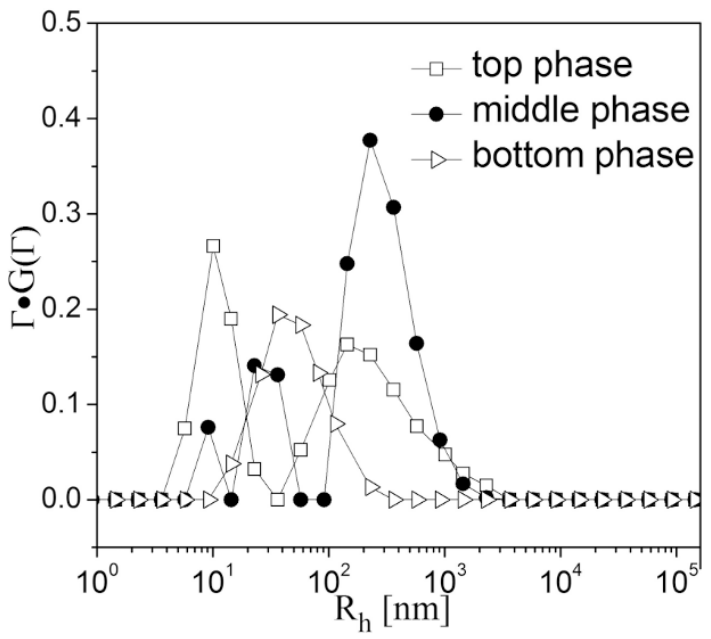

Figure $2 \mid$ DLS CONTIN plots of Texapon $\mathrm{N}_{70} / \mathrm{C}_{14} \mathrm{DMAO} / \mathrm{HCOOH} /$ $\mathrm{H}_{2} \mathrm{O}$ system performed at scattering angle of $90^{\circ}$. ellipsoidal objects (Fig. 3c), as the typical characteristic of the sponge $\mathrm{L}_{3}$ phase, was observed by the freeze-fracture TEM (FF-TEM). The sponge structure comprises highly interconnected bicontinuous bilayers $^{22,23}$. However, unlike the lamellar phase, the $\mathrm{L}_{3}$ phase presents no long-range order without static birefringence. Finally, compared with the slightly bluish top and middle phases, the bottom phase is clear and transparent, consisting of isolated nanodiscs ranging from 15 to $35 \mathrm{~nm}$ (Fig. 3d).

From the top vesicle phase ( $\mathrm{L} \alpha$ ') to the bottom disc phase $\left(\mathrm{L}_{1}{ }^{\prime}\right)$ in the $\mathrm{LA} / \mathrm{C}_{12} \mathrm{EO}_{4} / \mathrm{H}_{2} \mathrm{O}$ system, the solution density increases from $0.828 \mathrm{~g} \mathrm{~cm}^{-3}$ to $0.985 \mathrm{~g} \mathrm{~cm}^{-3}$ and to $1.021 \mathrm{~g} \mathrm{~cm}^{-3}$, with the middle sponge phase $\left(\mathrm{L}_{3}\right)$ taking up the largest volume fraction (Table 1). In this anionic/nonionic system, no counter ion is explicitly produced by the interaction of the two surfactants, thus, no excess salt is present. Though the spatial arrangement of surfactant molecules differs greatly from the vesicles to sponge to nanodiscs, and the size distribution ranges from tens of $\mathrm{nm}$ to even $\mu \mathrm{m}$, three completely different bilayer aggregates coexist in a single surfactant solution to reach dynamic equilibrium. The competition between the fluctuation of

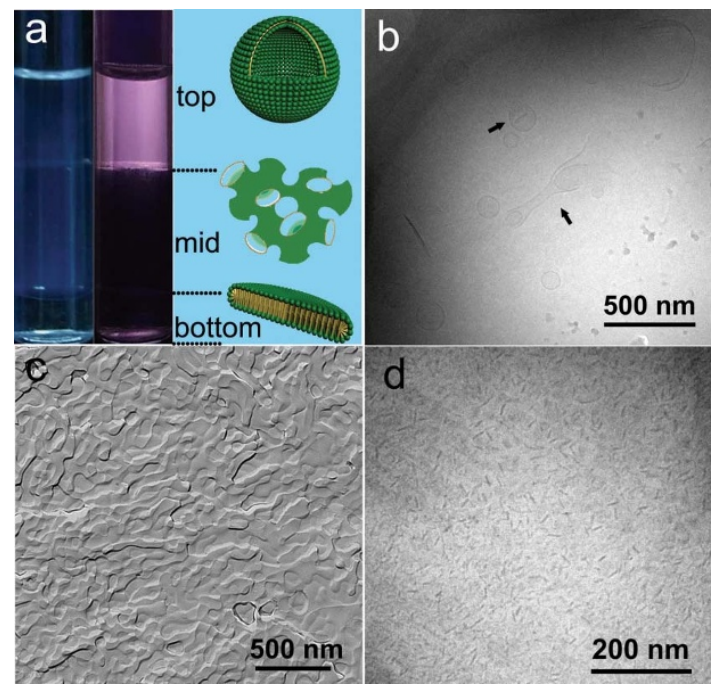

Figure 3 Molecular aggregates of A3PS observed in $\mathrm{LA} / \mathrm{C}_{12} \mathrm{EO}_{4} / \mathrm{H}_{2} \mathrm{O}$ at $25^{\circ} \mathrm{C}$. (a) Optical photographs of three-phase samples with and without crossed polarizers. (b) Unilamellar vesicles (50 to $120 \mathrm{~nm}$ in diameter) in the top phase. The arrows in image (b) show the fusion of small vesicles. (c and d) Sponge and nanodiscs (15 to $35 \mathrm{~nm}$ ) in the middle and bottom phases, respectively. 
membranes and unscreened electrostatic repulsion is believed to favor the spontaneous formation of highly stable multicomponent and multiscale bilayer aggregates. These results also illustrate that the presence of excess salt is not a crucial factor for the formation of A3PS.

A3PS in anionic/cationic system of SL/TTABr/ $\mathrm{H}_{2} \mathrm{O}$. In the above pair of A3PSs, a common feature is that the assemblies are negatively charged and stable in acidic solution. To determine whether a net surface charge and acidic environment are necessary conditions for A3PS, we reexamined the most common anionic/cationic surfactant system, that is, an $\mathrm{SL} / \mathrm{TTABr} / \mathrm{H}_{2} \mathrm{O}$ system possessing a basic $\mathrm{pH}$ in the cationic-rich region. Previously ${ }^{24}$, a three-phase region for this system was not reported because the possibility of multiple equilibrium phases was ignored. Upon more careful examination, a three-phase separation was found in a rather narrow region between a micelle/lamella two-phase region $\left(\mathrm{L}_{1} / \mathrm{L} \alpha\right)$ and a vesicle phase $(\mathrm{L} \alpha)$ in the cationic-rich region of the system (see Fig. S4 for the partial phase diagram).

In a sample of $\mathrm{SL} / \mathrm{TTABr} / \mathrm{H}_{2} \mathrm{O}\left(c_{\mathrm{T}}=100 \mathrm{mM}\right.$ and $\left.R_{\mathrm{nSL}}=0.395\right)$, a birefringent top phase coexists with a slightly bluish middle phase and a clear transparent bottom phase (Fig. 4a). Elemental analysis showed that the SL/TTABr ratio changes from 0.62 to 0.57 to 0.82 from top to bottom, gradually approaching a $1: 1$ ratio. This indicates that the net surface charge of the system decreases in the bottom phase while cationic surfactants remain in excess. The corresponding $\mathrm{pH}$ value is $8.8 \pm 0.2$. In this basic environment, large curved lamellas form in the top phase (Fig. 4b); the lamellas are not closed and slightly fluctuate. Excess cationic surfactant leads to a positively charged membrane and help to suppress undulations, thereby stabilizing the bilayer structure. With the increase of the net charge in the middle phase, a balance between electrostatic repulsion and mixing entropy is disturbed until the structures have transformed into short threadlike micelles (Fig. 4c). As the SL/TTABr ratio is close to unity in the bottom phase, multilamellar and unilamellar vesicles form (Fig. 4d). DLS performed on this sample at $90^{\circ}$ and $60^{\circ}$ confirm the formation of spherical vesicles with mean hydrodynamic radii of $400 \mathrm{~nm}$ (Fig. 4e).

This system demonstrates the presence of a lamella/micelle/vesicle $\left(\mathrm{L} \alpha / \mathrm{L}_{1} / \mathrm{L} \alpha^{\prime}\right)$ three-phase equilibrium in cationic-rich basic solution. In addition, by removing the excess salt $(\mathrm{NaBr})$ produced by the two surfactants through ion exchange, another salt-free catanionic
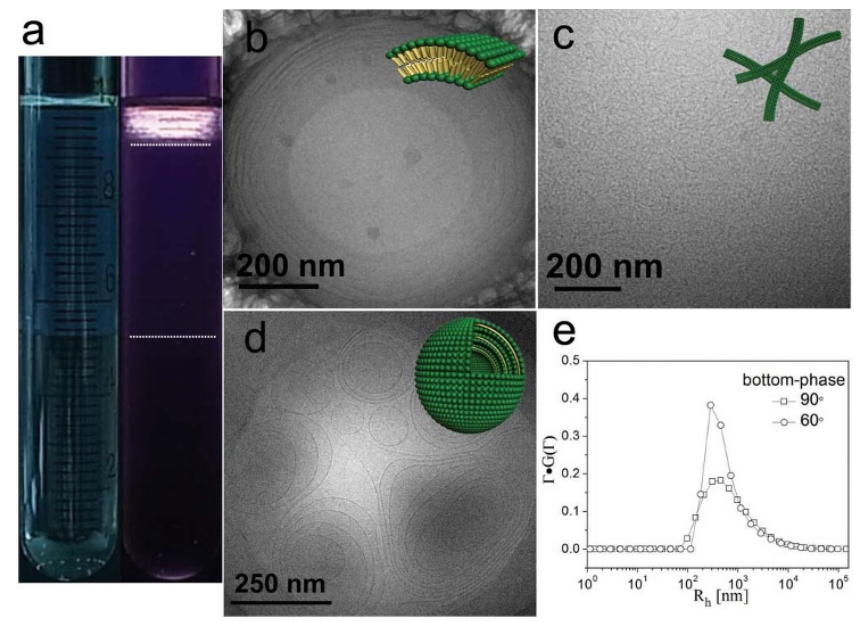

Figure $4 \mid$ Molecular aggreagtes of A3PS observed in $\mathrm{SL} / \mathrm{TTABr} / \mathrm{H}_{2} \mathrm{O}$ at $20^{\circ} \mathrm{C}$. (a) Optical photographs of three-phase samples with and without crossed polarizers. The two dot lines separated the three phases. (b, $\mathrm{c}$ and $\mathrm{d}$ ) Cryo-TEM images of curved bilayers, threadlike micelles and vesicles in the top, middle and bottom phases of sample (a), respectively. (e) DLS results of the bottom phase performed at scattering angles of $90^{\circ}$ and $60^{\circ}$. system, TTA ${ }^{+-} \mathrm{L}$ with $\mathrm{H}^{+}$and $\mathrm{OH}^{-}$as counter ions, may be obtained $^{25}$. As expected, an obvious three-phase is formed in a rather narrow $\mathrm{TTA}^{+}$-rich basic region of this salt-free system with birefringent lamellar top and middle phases, coexisting with a clear micellar bottom phase. These systems demonstrate that A3PSs may be formed in acidic or basic solution, but, as above, a resulting net surface charge, especially as partial charge separation, seems to favor the formation of A3PS.

General properties of A3PS. A common feature of A3PS is that the total concentration and the surfactant ratio not only contributes to its formation, but also affects the resulting, different phase volumes (Fig. $\mathrm{S} 5$ a to f). For example, in the $100 \mathrm{mM} \mathrm{C}_{14} \mathrm{DMAO} / \mathrm{Texapon} \mathrm{N}_{70}$ / $\mathrm{HCOOH} / \mathrm{H}_{2} \mathrm{O}$ system, the phase transition is so sensitive to the anionic/cationic ratio that the volume of the mid lamellar phase drastically increased 8 fold (from $0.5 \mathrm{~mL}$ to $4.0 \mathrm{~mL}$ ) when the Texapon $\mathrm{N}_{70}$ concentration increased by $0.3 \mathrm{mM}$ (Fig. S5a). In the three-phase region of the $\mathrm{LA} / \mathrm{C}_{12} \mathrm{EO}_{4} / \mathrm{H}_{2} \mathrm{O}$ system at constant $R_{\mathrm{LA}}=$ 0.25 , but with an increase of total surfactant concentration from $13 \%$ to $30 \%$, the volume fraction of the top vesicle phase ( $\mathrm{L} \alpha$ ) gradually increases, while the middle sponge phase $\left(\mathrm{L}_{3}\right)$ and the bottom nanodisc phase $\left(\mathrm{L}_{1}^{\prime}\right)$ decreases (Fig. S5c). In another three-phase sample of $\mathrm{SL} / \mathrm{TTABr} / \mathrm{H}_{2} \mathrm{O}$ at a constant total concentration of $100 \mathrm{mM}$, as $R_{\mathrm{nSL}}$ increases from 0.39 to 0.40 , the phase volume of the middle phase continually decreases while the top and bottom phases become larger until merging into a single homogenous phase (Fig. S5e and f). Hence, the production of expected A3PS requires precise control of the mixed surfactant concentrations and ratios.

A3PS is also very sensitive to temperature; for the three systems reported here, a constant temperature between 20 to $30^{\circ} \mathrm{C}$ favors the formation of the three-phase system (Fig. 5a to c), a favorable range for bioprocesses applications. Also favorable is the wider range of three-phase separation temperatures ( $T s$ ) potentially available. In the $\mathrm{C}_{14} \mathrm{DMAO} /$ Texapon $\mathrm{N}_{70} / \mathrm{HCOOH} / \mathrm{H}_{2} \mathrm{O}$ mixture, the three-phase system is stable to $16^{\circ} \mathrm{C}$ (Fig. $5 \mathrm{a}$ ), while the $\mathrm{SL} / \mathrm{TTABr} / \mathrm{H}_{2} \mathrm{O}$ system exhibits a stable three-phase up to $36^{\circ} \mathrm{C}$ (Fig. $5 \mathrm{c}$ ). Out of an appropriate Ts range, A3PS will be remixed to form an A2PS. Interestingly, the three systems each behave with similar transitions with temperature; with a decrease in temperature, one phase among the three phases is compressed, finally leading to the formation of $L \alpha / \mathrm{L}_{1}$ twophase. For example, a typical phase transition from an $\mathrm{L} \alpha^{\prime} / \mathrm{L}_{3} / \mathrm{L}_{1}{ }^{\prime}$ three-phase to an $\mathrm{L} \alpha / \mathrm{L}_{1}$ two-phase from 25 to $18^{\circ} \mathrm{C}$ is shown in

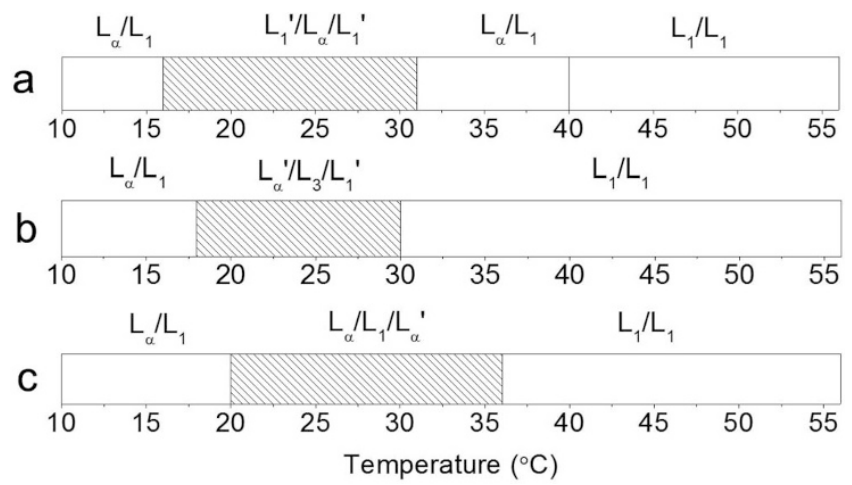

Figure $5 \mid$ Observed phase behavior of surfactant mixtures as a function of temperature. The three-phase of the $100 \mathrm{mM} \mathrm{C}_{14} \mathrm{DMAO} / 26.5 \mathrm{mM}$ Texapon $\mathrm{N}_{70} / 26.5 \mathrm{mM} \mathrm{HCOOH} / \mathrm{H}_{2} \mathrm{O}$ system appears between 16 and $31{ }^{\circ} \mathrm{C}$ (a). In the $\mathrm{LA} / \mathrm{C}_{12} \mathrm{EO}_{4} / \mathrm{H}_{2} \mathrm{O}$ system $\left(W_{\mathrm{T}}=23 \% ; R_{\mathrm{LA}}=0.25\right)$ the three-phase region exists from 18 to $30^{\circ} \mathrm{C}$ (b). Finally, the SL/TTABr $/ \mathrm{H}_{2} \mathrm{O}$ system $\left(c_{\mathrm{T}}=100 \mathrm{mM} ; R_{\mathrm{nSL}}=0.395\right)$ has a three-phase region that exists from 20 to $36^{\circ} \mathrm{C}$ (c). 
Fig. S6. On the other hand, with increasing temperature, one lamellar phase gradually disappears to form a micellar phase.

Here, the general trend of phase transition from a lamellar phase to a micellar phase is ascribed to the dehydration of the surfactant head groups with increasing temperature due to unfavorable entropy contributions, which favor micelle formation. Temperature has great effect on the behavior of $\mathrm{C}_{12} \mathrm{EO}_{4}$ and heating usually induces its aqueous solution phase separation. Especially as the $\mathrm{C}_{12} \mathrm{EO}_{4}$ cloud point is approached, the micelles in the system grow into branched micelles in the subsequent connected network structure ${ }^{13}$. $\mathrm{C}_{14} \mathrm{DMAO}$, a special nonionic surfactant, has no cloud point but it also shows a temperature-dependence in aggregate size, that is, a sphere/rod transition occurs with increasing temperature ${ }^{26}$. In contrast, in ionic surfactant systems the aggregate size usually decreases when temperature increases. However, for the cation-rich SL/ $\mathrm{TTABr} / \mathrm{H}_{2} \mathrm{O}$ system, strong electrostatic interactions between the anionic and cationic surfactants cause the ion pairs to exhibit similar properties to nonionic surfactants ${ }^{27}$. Furthermore, with increasing temperature, counter ions located near the lamellas begin to move away, leaving the lamellas more positive, ultimately leading to a change in membrane curvature.

The partitioning and effects of dyes on the A3PS phase behavior was examined. After addition of different types of dyes (see Fig. S7) into the $\mathrm{L}_{1} / \mathrm{L} \alpha / \mathrm{L}_{1}$ ' three-phase solution of $26.5 \mathrm{mM}$ Texapon $\mathrm{N}_{70} /$ $100 \mathrm{mM} \mathrm{C}_{14} \mathrm{DMAO} / 26.5 \mathrm{mM} \mathrm{HCOOH}$, samples were left to equilibrate for one week at $25^{\circ} \mathrm{C}$ (Fig. S8a to d). When a single dye was added, the $\mathrm{L}_{1} / \mathrm{L} \alpha / \mathrm{L}_{1}$ ' three-phase still existed, but the phase volume changed compared to the initial mixture. Specifically, the addition of the slightly water-soluble dye, Methyl Orange, at room temperature resulted in the drastic compression of the middle phase while the top phase grew (Fig. S8a). In contrast, the oil-soluble azobenzene induced an expansion of the middle phase while the bottom phase diminished (Fig. S8b) and led to a more obvious birefringent texture in the $\mathrm{L} \alpha$ phase. The three phases are in equilibrium and each component of the phase has the same chemical potential in each of the three phases. Therefore, the strong colour intensity due to the solubilization of azobenzene also gives a good support that the lamellar phase has a higher surfactant concentration than the other two phases. When a mixture of two different dyes was added to the three-phase solution, a phase transition was triggered forming a fourth phase on top of A3PS with obvious birefringence. Fig. S8c shows the aqueous four-phase sample after addition of oil-soluble Sudan II and water-soluble Methylene Blue. The positively charged Methylene Blue is dissolved in all of the four phases and its dark blue color covers that of Sudan II. When Methylene Blue is replaced by oil-soluble fluorescein, both of the oil-soluble dyes are concentrated in the upper three surfactant-rich phases (Fig. S8d). Cryo-TEM images indicated that unilamellar and multilamellar vesicles coexist in the topmost fourth phase (Fig. S8e and f), confirming the formation of a new vesicle/discs/lamella/disc four-phase (an A4PS) colloid system.

One-step synthesis and separation of multiscale CdS nanowires. Colloidal solutions, including micelles ${ }^{28}$, vesicles ${ }^{29}$, and so on, have been regarded as efficient templates for controlling the size and shape of particle and nanostructure synthesis. Here, A3PS was exploited as a media for the one-step production and separation of CdS nanorods, nanowires and straw-like bundles via precipitation from solution. As a model system, a desired amount of $\mathrm{Cd}\left(\mathrm{CH}_{3} \mathrm{COO}\right)_{2}$ solution, as $\mathrm{Cd}$ precursor, was mixed with $\mathrm{C}_{14} \mathrm{DMAO}$, Texapon $\mathrm{N}_{70}$, and $\mathrm{HCOOH}$ to form a stable A3PS containing $5 \mathrm{mM} \mathrm{Cd}\left(\mathrm{CH}_{3} \mathrm{COO}\right)_{2}, 100 \mathrm{mM}$ $\mathrm{C}_{14}$ DMAO, $26.5 \mathrm{mM}$ Texapon $\mathrm{N}_{70}$, and $26.5 \mathrm{mM} \mathrm{HCOOH}$. Next, the precipitation reaction was performed with the addition of a stoichiometric amount of thioacetamide to the three-phase solution followed by dissolution using ultrasound at $30^{\circ} \mathrm{C}$ for $72 \mathrm{~h}$. This process slowly releases sulfide $\left(\mathrm{S}^{2-}\right)$ that reacts with $\mathrm{Cd}^{2+}$ to form CdS. The A3PS is preserved after the reaction and brightyellow CdS precipitates are dispersed in the solution (Fig. 6a, IIV). The purified CdS products in the top (I), middle (II), and bottom phases (III), as well as at the bottom of sample tube (IV) were characterized.

Fig. 6 (b, e, h and j) illustrates an interesting evolution in the shapes and sizes of the inorganic products. In region I, apparently influenced by the nanodiscs, the reaction yielded short CdS nanorods (Fig. 6b). Selected-area electron diffraction (SAED) patterns of the nanorods show the presence of characteristic patterns for the CdS (101), (102), and (202) planes (Fig. 6c), in which the (101) ring shows a preferential orientation. These nanorods have lengths ranging from 50 to $170 \mathrm{~nm}$ (see size distribution curve, Fig. 6d), and a uniform diameter of $\sim 16 \mathrm{~nm}$. The formation of nanorods may be understood as arising from the nucleation of $\mathrm{Cd}^{2+}$ and $\mathrm{S}^{2-}$ easily occurring along the edge of the nanodiscs. This is because $\mathrm{Cd}^{2+}$ ions are expected to populate this edge due to the existence of the partial excess negative charge, thereby stabilizing the highly curved interfaces. Capping surfactant adsorption and crystal growth kinetics may then account for the formation of the short nanorods. In region II, CdS nanorods with a higher aspect ratio of 10 were obtained (Fig. 6e). These rods have a mean length of $196 \mathrm{~nm}$ and a uniform width of $20 \mathrm{~nm}$ and grew along the (100) direction (Fig. $6 \mathrm{f}$ and g). The larger, negatively charged bilayer fragments in this phase are appropriate for this further growth of CdS nanorods.

Fig. 6h shows the CdS crystals obtained in region III; The associated SAED patterns show multiple characteristic diffraction rings for CdS (100), (102), (110), (200), and (104) planes (Fig. 6i). The strong (100) diffraction indicates the $1 \mathrm{D}$ growth of CdS nanocrystals. Long CdS nanowires with a uniform width of $\sim 30 \mathrm{~nm}$ are the primary product. The length of CdS nanowires ranged from $1 \mu \mathrm{m}$ to $2 \mu \mathrm{m}$, but could be as long as $4 \mu \mathrm{m}$, leading to a high aspect ratio

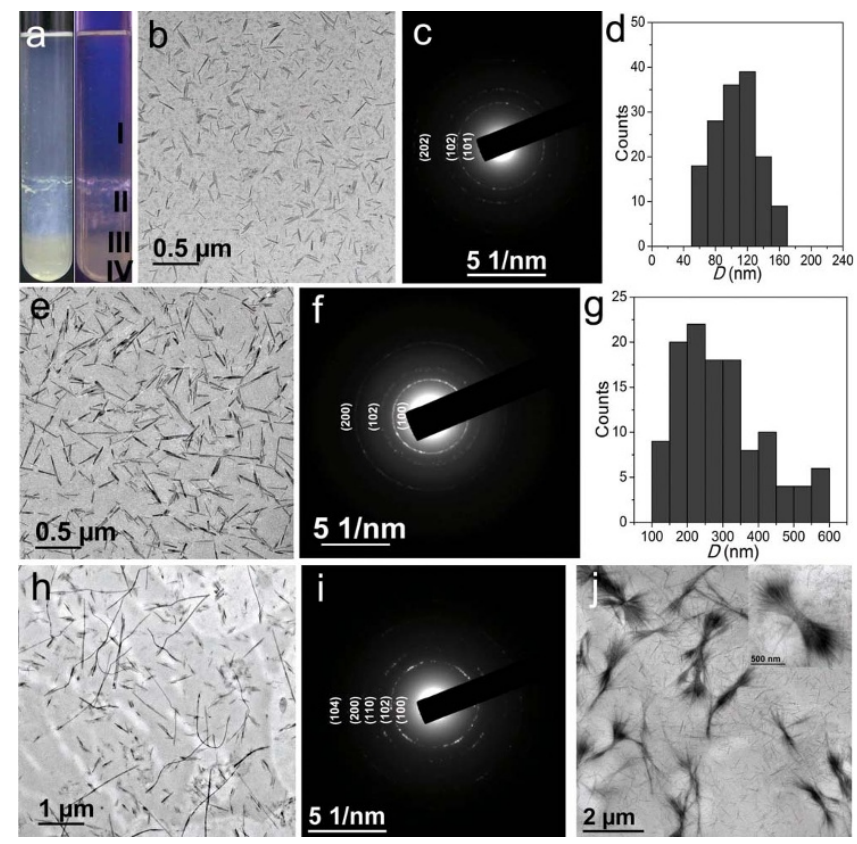

Figure 6 Characterization of CdS crystals produced in a three-phase sample of $100 \mathrm{mM} \mathrm{C}_{14} \mathrm{DMAO} / 26.5 \mathrm{mM}$ Texapon $\mathrm{N}_{70} / 26.5 \mathrm{mM}$ $\mathrm{HCOOH} / \mathrm{H}_{2} \mathrm{O}$. Optical photograph (a) of the three-phase sample after CdS formation with and without crossed polarizers. I, II, III, and IV mark the top, middle, and bottom phases, and precipitates in the bottom of the sample tube, respectively. TEM images (b, e, h, and j) of CdS crystals found in domains I, II, III, and IV of sample (a), respectively. SAED patterns with diffraction rings of obtained CdS (c, f, and i) corresponding to images (b, e, and h), respectively. Size distribution of CdS nanorod length (d and $\mathrm{g}$ ), corresponding to images (b and e), respectively. 
over 130. The nanowires are flexible enough that they can bear the strain caused by bending. The transition from nanorods into nanowires from the top phase to bottom phase may be accounted for by the more negatively charged nanodiscs in the bottom phase compared with the assemblies in the other phases. This would lead to stronger binding with $\mathrm{Cd}^{2+}$, resulting in the most concentrated $\mathrm{Cd}$ precursor. Finally, the precipitates at the bottom of the three-phase solution were found to be CdS whiskers bundled like straw sheaves with lengths of $\sim 2 \mu \mathrm{m}$ (Fig. 6j). A crystal splitting growth mechanism is believed to describe the formation of the $3 \mathrm{D}$ straw-sheaf structures. During the continuous growth of CdS nanowires, newly formed CdS nuclei preferentially adsorb on the ends of the nanowires rather than the in the center, leading to bifurcated growth. Actually, the morphological evolution from nanorods to nanowires to straw bundles is a common phenomenon during crystal growth and may be achieved by sequential reaction additions ${ }^{30}$. Here, a simple, mild one-step precipitation from A3PS can produce and separate multiscale CdS nanowires.

\section{Discussion}

On the basis of the above experiments, we demonstrate the general validity of forming aqueous three-phase surfactant systems (A3PS) by mixing common single-tailed anionic/nonionic or anionic/cationic surfactants with appropriate chain length and headgroup size. Taken together, these systems reveal some principles related to A3PS. First, A3PS is a spontaneous three-phase form within thermodynamic and dynamic equilibrium in colloid science. The A3PS may be stored with little change for one to two years under appropriate conditions. Complex multistructural and multiscale self-assemblies coexist in the A3PS and help stabilize the phases. The ordered structures and the surfactant compositions influence the resulting viscosity and phase volume fraction. Second, A3PS usually appears in a rather narrow domain of a surfactant system's phase diagram that may be easily neglected. Precise control of the total concentration and the surfactant ratio is a basic procedure for the formation of A3PS. The net surface charge produced by the unpaired anionic or cationic surfactant, especially that exhibiting partial charge separation, favors self-assembly of multiple and multiscale ordered structures and helps to stabilize them in the multiphase system. Third, appropriate temperature is another basic factor in the formation of A3PS through its influence on the interfacial balance between the aggregates and water. In the present study, a ten degree range centered around $25^{\circ} \mathrm{C}$ was common to the three-phase systems, while various systems were stable over ranges including 16 to $35^{\circ} \mathrm{C}$. Other factors, including the presence of salt, $\mathrm{pH}$, or additives, of course, can influence the phase behavior of A3PS, but are not basic to the formation of A3PS.

In conclusion, the systems presented here enrich the area of surfactant self-assembly in colloid chemistry and outline a general strategy for the characterization and development of A3PSs, as well as providing a better understanding of parameters needed to tailor the properties of three-phase systems for different purposes. Such systems may provide new separation and extraction systems for biomaterials or other molecules, and may allow for one-step synthesis and separation of inorganic materials with complex topologies and multiple scales under mild conditions. A3PS also provides a potential strategy for synthesis with fewer purification steps, that is, during the reaction the resulting product may be condensed in one phase while residual reactants, coproducts or waste is simultaneously separated in the other phases.

\section{Methods}

Determination of phase composition. Samples of each of the three phases were individually removed using a micropipettor. Each phase solution sample was frozen at $-50^{\circ} \mathrm{C}$ and dried in a vacuum desiccator for three days, then weighed and analyzed by elemental analysis (Elementar Vario EI III, Germany).
Dynamic light scattering (DLS) measurements. DLS was carried out at scattering angles of $90^{\circ}$ and $60^{\circ}$. A standard Brookhaven Commercial laser light scattering spectrometer equipped with a Coherent Radiation $200 \mathrm{~mW}$ diode pumped solid-state (DPPS) $488 \mathrm{~nm}$ laser and a Brookhaven Instruments Corporation (BI-9000AT) correlator were used for the measurements. The obtained data were analyzed by CONTIN $^{19}$

Cryogenic transmission electron microscopy (cryo-TEM) observations. Aggregate structures in the low-viscosity solution were determined by cryo-TEM. The samples were prepared in a controlled-environment vitrification system (Cryoplunge TM3, Gatan, USA) at $25^{\circ} \mathrm{C}$ at $95 \%$ relative humidity. A micropipette was used to load a $1 \mu \mathrm{L}$ aliquot of solution from each phase onto a copper grid coated with carbon film. The excess solution was blotted with two pieces of filter paper, resulting in the formation of thin films suspended on the mesh holes. After $10 \mathrm{~s}$ the grid, with sample, was quickly plunged into liquid ethane cooled by liquid nitrogen. The vitrified sample was transferred to a cryogenic specimen holder (Gatan 626), and examined on a JEOL JEM 1400 TEM operating at $120 \mathrm{KV}$.

Freezing-fracture transmission electron microscopy (FF-TEM) observations. The structure of a $\mathrm{L}_{3}$-phase is very difficult to determine from cryo-TEM. A better picture could be obtained by FF-TEM ${ }^{23}$. A small amount of $\mathrm{L}_{3}$-phase solution was mounted on a specimen holder. The sample was frozen by quickly plunging the specimen holder into liquid ethane cooled by liquid nitrogen. Fracturing and replication were carried out on a freeze-fracture apparatus (EM BAF 060, Leica, Germany) at a temperature of $-150^{\circ} \mathrm{C}$. $\mathrm{Pt} / \mathrm{C}$ was deposited at an angle of $45^{\circ}$ to shadow the replicas and $\mathrm{C}$ was deposited at an angle of $90^{\circ}$ to consolidate the replicas. The replicas were transferred onto copper grid and then observed using a JEOL JEM-1400 TEM operated at $120 \mathrm{kV}$

Synthesis of multiscale CdS nanowires. An appropriate amount of aqueous $\mathrm{Cd}\left(\mathrm{CH}_{3} \mathrm{COO}\right)_{2} \cdot 2 \mathrm{H}_{2} \mathrm{O}$ stock solution was prepared. A specified volume of the $\mathrm{Cd}$ stock solution was mixed with Texapon $\mathrm{N}_{70}, \mathrm{C}_{14} \mathrm{DMAO}$, and $\mathrm{HCOOH}$ to form an aqueous three-phase sample containing $5 \mathrm{mM} \mathrm{Cd}\left(\mathrm{CH}_{3} \mathrm{COO}\right)_{2}, 100 \mathrm{mM} \mathrm{C}_{14} \mathrm{DMAO}$, $26.5 \mathrm{mM}$ Texapon $\mathrm{N}_{70}$, and $26.5 \mathrm{mM} \mathrm{HCOOH}$. The three-phase sample was placed in a thermostat-controlled oven at $25^{\circ} \mathrm{C}$ for at least four weeks, resulting in the phase behavior. Following the equilibration time, a stoichiometric amount of thioacetamide was added to the three-phase mixture and dissolved using $40 \mathrm{~Hz}$ ultrasound at $30^{\circ} \mathrm{C}$ for $72 \mathrm{~h}$. This slowly releases sulfide $\left(\mathrm{S}^{2-}\right)$, which reacts with $\mathrm{Cd}^{2+}$ to form $\mathrm{CdS}$. The three-phase mixture was not disturbed by the ultrasound or after the reaction (as shown in Fig. 6a). After the reaction was complete, samples of each of the three phases were carefully removed with a micropipettor. A small volume of chloroform was added to each sample phase to prevent solidification. Bright-yellow precipitates were separated from the crude mixtures by centrifugation and rinsed with ethanol repeatedly. The purified product was redispersed in chloroform for further characterization.

1. Whitesides, G. M. \& Grzybowski, B. Self-assembly at all scales. Science $\mathbf{2 9 5}$ 2418-2421 (2002).

2. Moore, J. S. \& Kraft, M. L. Synchronized self-assembly. Science 320, 620-621 (2008).

3. Hoffmann, H. Fascinating Phenomena in Surfactant Chemistry. Adv. Mater. 6, 116-129 (1994).

4. Groschel, A. H. et al. Precise hierarchical self-assembly of multicompartment micelles. Nature Comm. 1-10 (2012).

5. Zemb, T., Dubois, M., Deme, B. \& Gulik-Krzywicki, T. H. Self-assembly of flat nanodiscs in salt-free catanionic surfactant solutions. Science 283, 816-819 (1999).

6. Kaler, E. W., Murthy, A. K., Rodriguez, B. E. \& Zasadzinski, J. Spontaneous vesicle formation in aqueous mixtures of single-tailed surfactants. Science 245, 1371-1374 (1989).

7. Yan, D., Zhou, Y. \& Hou, J. Supramolecular self-assembly of macroscopic tubes. Science 303, 65-67 (2004).

8. Hartgerink, J. D., Beniash, E. \& Stupp, S. I. Self-assembly and mineralization of peptide-amphiphile nanofibers. Science 294, 1684-1688 (2001).

9. Albertsson, P.-A. Partition of proteins in liquid polymer-polymer two-phase systems. Nature 182, 709-711 (1958).

10. Sikdar, S. K. Aqueous two-phase extraction in bioseparations: an assessment. Nature 9, 253-256 (1991).

11. Long, M. S. \& Keating, C. D. Nanoparticle conjugation increases protein partitioning in aqueous two-phase systems. Anal. Chem. 78, 379-386 (2006).

12. Benavides, J., Aguilar, O., Lapizco-Encinas, B. H. \& Rito-Palomares, M. Extraction and purification of bioproducts and nanoparticles using aqueous two-phase systems strategies. Chem. Eng. Technol. 31, 838-845 (2008).

13. Dong, R. \& Hao, J. Complex fluids of poly(oxyethylene) monoalkyl ether nonionic surfactants. Chem. Rev. 110, 4978-6022 (2010).

14. Kamei, D. T., Wang, D. I. C. \& Blankschtein, D. Fundamental investigation of protein partitioning in two-phase aqueous mixed (nonionic/ionic) micellar systems. Langmuir 18, 3047-3057 (2002).

15. Yatcilla, M. T. Phase behavior of aqueous mixtures of cetyltrimethylammonium bromide (CTAB) and sodium octyl sulfate (SOS). J. Phys. Chem. 100, 5874-5879 (1996). 
16. Ghosh, O. \& Miller, C. A. Liquid-crystalline and microemulsion phase behavior in alcohol-free aerosol-OT/oil/brine systems. J. Phys. Chem. 91, 4528-4535 (1987).

17. Hao, J., Hoffmann, H. \& Horbaschek, K. A vesicle phase that is prepared by shear from a novel kinetically produced stacked L $\alpha$-phase. J. Phys. Chem. B 104, 10144-10153 (2000)

18. Olsson, U., Nakamura, K., Kunieda, H. \& Strey, R. Normal and reverse vesicles with nonionic surfactant: solvent diffusion and permeability. Langmuir 12, 3045-3054 (1996).

19. Provencher, S. W. Contin: a general purpose constrained regularization program for inverting noisy linear algebraic and integral equations. Comput. Phys. Commun. 27, 229-242 (1982).

20. Jung, H. T. et al. Gaussian curvature and the equilibrium among bilayer cylinders, spheres, and discs. Proc. Natl. Acad. Sci. U. S. A. 99, 15318-15322 (2002).

21. Almgren, M., Edwards, K. \& Karlsson, G. Cryo transmission electron microscopy of liposomes and related structures. Colloids Sur. A 174, 3-21 (2000).

22. Hough, L. E., et al. Chiral isotropic liquids from achiral molecules. Science 325, 452-456 (2009).

23. Zapf, A., Hornfeck, U., Platz, G. \& Hoffmann, H. Investigation of the $\mathrm{L}_{3}$ phase in system containing calcium dodecyl sulfate, alcohol, and water. Langmuir 17, 6113-6118 (2001).

24. Horbaschek, K., Hoffmann, H. \& Hao, J. Classic L $\alpha$ phases as opposed to vesicle phases in cationic-anionic surfactant mixtures. J. Phys. Chem. B 104, 2781-2784 (2000).

25. Li, H. \& Hao, J. Phase behavior and rheological properties of a salt-free catanionic surfactant TTAOH/LA/H ${ }_{2} \mathrm{O}$ system. J. Phys. Chem. B 112, 10497-10508 (2008).

26. Hoffmann, H., Oetter, G. \& Schwandner, B. The aggregation behaviour of tetradecyldimethylaminoxide. Prog. Colloid Polym. Sci. 73, 95-106 (1987).

27. Hassan, P. A. et al. Vesicle to micelle transition: rheological investigations. Langmuir 12, b 4350-4357 (1996).

28. Pileni, M. P. The role of soft colloidal templates in controlling the size and shape of inorganic nanocrystals. Nat. Mater. 2, 145-150 (2003)
29. Dong, R., Liu, W. \& Hao, J. Soft vesicles in the synthesis of hard materials. Acc. Chem. Res. 45, 504-513 (2012).

30. Deng, H. et al. Additive-mediated splitting of lanthanide orthovanadate nanocrystals in water: morphological evolution from rods to sheaves and to spherulites. Cryst. Growth Des. 8, 4432-4439 (2008).

\section{Acknowledgements}

This work was financially supported by the NSFC (Grant No. 21033005 \& 21273134), and the National Basic Research Program of China (973 Program, 2009CB930103). R. Dong acknowledges the Scholarship Award for Excellent Doctoral Student granted by the Ministry of Education of R. P. China. J. Hao thanks Prof. Dr. Heinz Hofmann and Prof. Dr. J. David Van Horn (Visiting Professors, Shandong University) for editorial assistance.

\section{Author contributions}

R.D. designed and carried out the work and he guided that L.Z. contributed to prepare the solution samples of the $\mathrm{LA} / \mathrm{C}_{12} \mathrm{EO}_{4} / \mathrm{H}_{2} \mathrm{O}$ system. D.W. participated in some cryo-TEM experiments for the SL/TTABr system. J.H. guided the work and wrote the manuscript.

\section{Additional information}

Supplementary information accompanies this paper at http://www.nature.com/ scientificreports

Competing financial interests: The authors declare no competing financial interests.

License: This work is licensed under a Creative Commons

Attribution-NonCommercial-NoDerivs 3.0 Unported License. To view a copy of this license, visit http://creativecommons.org/licenses/by-nc-nd/3.0/

How to cite this article: Dong, R.H., Zhou, L., Wang, D. \& Hao, J.C. Sci. Rep. 3, 1663 DOI:10.1038/srep01663 (2013) 